\title{
NATURAL RADIOCARBON VARIATIONS FROM AD 200 TO 800
}

\section{MICHAEL BRUNS*, K O MÜNNICH**, and BERND BECKER***}

ABSTRACT. High precision radiocarbon measurements $( \pm 2.5 \%$ STD) were carried out on absolutely dated European oak material. These showed that significant shortterm atmospheric ${ }^{14} \mathrm{C}$ variations of up to 2 percent occurred between $\mathrm{AD} 200$ and 800. These changes, reflecting a 150-to 180-year periodicity, seem to correlate with the average sunspot activity around that time. In comparison with results obtained by other authors, a very regular pattern of natural atmospheric ${ }^{14} \mathrm{C}$ variations is exhibited.

In $1970, \mathrm{H}$ E Suess presented his preliminary results of ${ }^{14} \mathrm{C}$ measurements of the Bristlecone Pine series. The significance of some of the short time variations in his curve drawn by "cosmic schwung" was largely questioned and caused much discussion (Suess, 1970b; Pearson and others, 1977). However, unlike other parameters in tree rings (for example, stable isotope variations) ${ }^{14} \mathrm{C}$ reliably represents the global atmosphere. This results from: 1) fast atmospheric mixing as demonstrated from spreading artificial nuclear weapon test ${ }^{14} \mathrm{C}$, and 2 ) in respect to ${ }^{14} \mathrm{C}$, the tree ring is simply a sampling device and generally not influenced by local climatic or meteorologic conditions, as intrinsic variations are eliminated by ${ }^{13} \mathrm{C}$ correction.

In addition, the world-wide correlation of natural ${ }^{14} \mathrm{C}$ has been directly shown experimentally by comparison of trees from Europe and America (Suess and Becker, 1977); most recently by de Jong, Mook, and Becker (1979); see also proceedings of this conference.

About 80 tree-ring samples have now been measured during the last two years using an absolutely dated dendrochronologic series of oak trees (Quercus sp) from gravel beds of rivers in Southern Germany. The time scale covered is from about $\mathrm{AD} 200$ to 800 , a period rather poorly defined by bristlecone pine measurements. Contrary to previous measurements by several authors, only 1 to 3 years were taken for one analysis, with at least one sample per decade, to provide a maximum resolution. Quercus sp shows broad rings and even single-year samples can easily be separated. From the chronology, consisting of more than 100 individual trees, four were chosen, so that the samples are overlapping. To avoid contamination of atmospheric ${ }^{14} \mathrm{C}$ by recycling soil $\mathrm{CO}_{2}$ during photosynthesis, no samples were taken from the innermost section of the trees ( $\leqslant 30$ years). A proportional counter with 10 liters (STP) of purified $\mathrm{CO}_{2}$ was used. The ${ }^{14} \mathrm{C}$ measuring precision of the present set of samples usually is about $\pm 2.5 \%$ STD corresponding to a ${ }^{14} \mathrm{C}$ age error of \pm 20 years (Schoch and others, 1980).

Figure 1 indicates the existence of pronounced wiggles between AD 250 and 750 of up to 2 percent in atmospheric radiocarbon content. These changes, with a rapid increase in about 30 to 50 years, followed by a slower decrease in about twice that time, may be attributed to changes in the atmospheric ${ }^{14} \mathrm{C}$ production rates of about 30 to 70 perSciences

* Research project "Dating of Water and Sediments" Heidelberg Academy of

** Institut für Umweltphysik der Universität Heidelberg, FRG

*** Botanisches Institut der Universität Hohenheim, FRG 
cent above an assumed steady state level by using a three box model according to Houtermans, Suess, and Oeschger (1973) with an atmospheric residence time $\tau_{\mathrm{AS}}$ of 10 years.

${ }^{14} \mathrm{C}$ variations of that size have been well established for the 16 th to the 19th century AD. For this period, a positive correlation of sunspot activity (Maunder and Spörer minimum) and climate (Little Ice Age), and an inverse correlation between sunspot activity and atmospheric ${ }^{14} \mathrm{C}$ content is well documented (Stuiver, 1961; Suess, 1968; Eddy, 1976; Stuiver, 1978). Unfortunately, direct proof of this relationship is impossible in the present set of data. This is due to the absence of detailed and continuous climatic and astronomical records. Some attempts, however, were made to establish the sunspot activity of ancient epochs (Bray, 1967) partly by using astronomical observations of aurorae and sunspots in the orient (Clark and Stephenson, 1978). Their investigations show several gaps in the order of 100 and 200 years in Far East sunspot records ("Maunder Minimum Type"). Indeed, these gaps coincide with increasing or high ${ }^{14} \mathrm{C}$ levels between $\mathrm{AD} 400$ to 500 and $\mathrm{AD} 600$ to 800 (bars, fig 1). A global climatic response cannot be proven. Regional trends seem to have occurred around that time but do not lead to a comprehensive global picture (Mitchell, 1977). In the whole series, consisting of more than 100 individual trees, the 5-year average of tree growth curves shows fluctuations reflecting the meteorologic conditions of the sites in which the trees were grown. This curve is positively correlated to the ${ }^{14} \mathrm{C}$ curve given as a 10-year running means of the samples (fig 2) (see Becker, 1980).

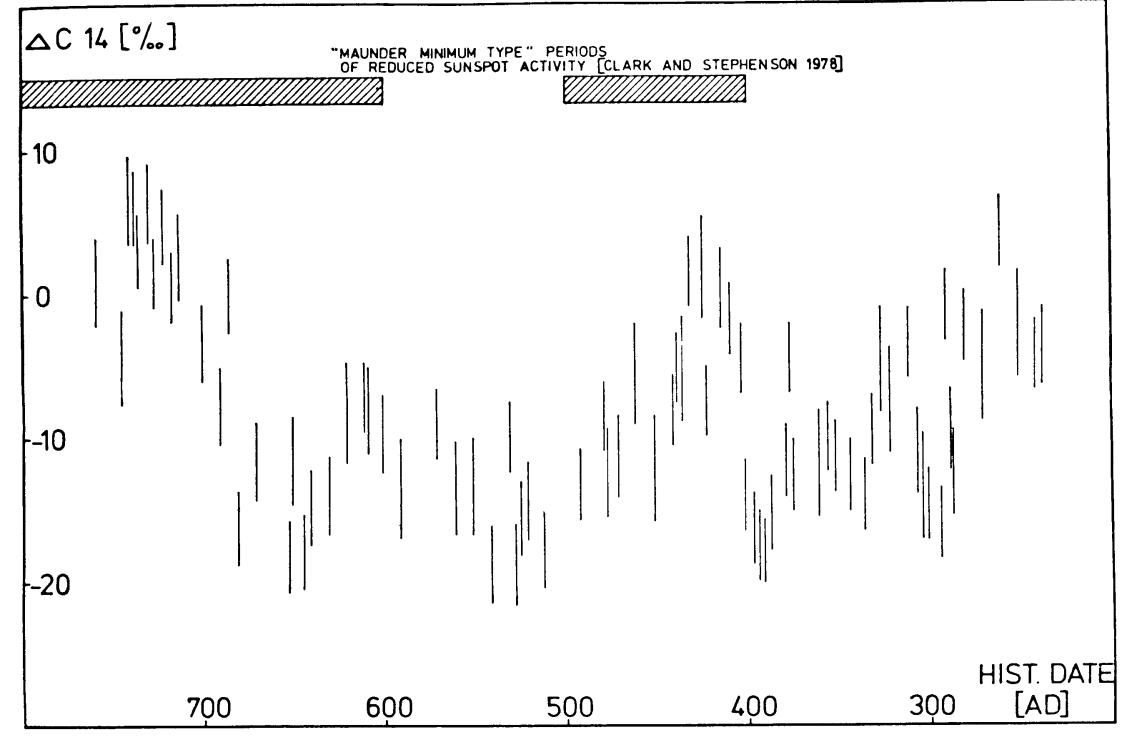

Fig $1 . \Delta^{14} \mathrm{C}[\%] \tau=5730$ years from AD 200 to 800 in absolutely dated European oak series. Bars represent periods of reduced sunspot activity (Clark and Stephenson, 1978). 


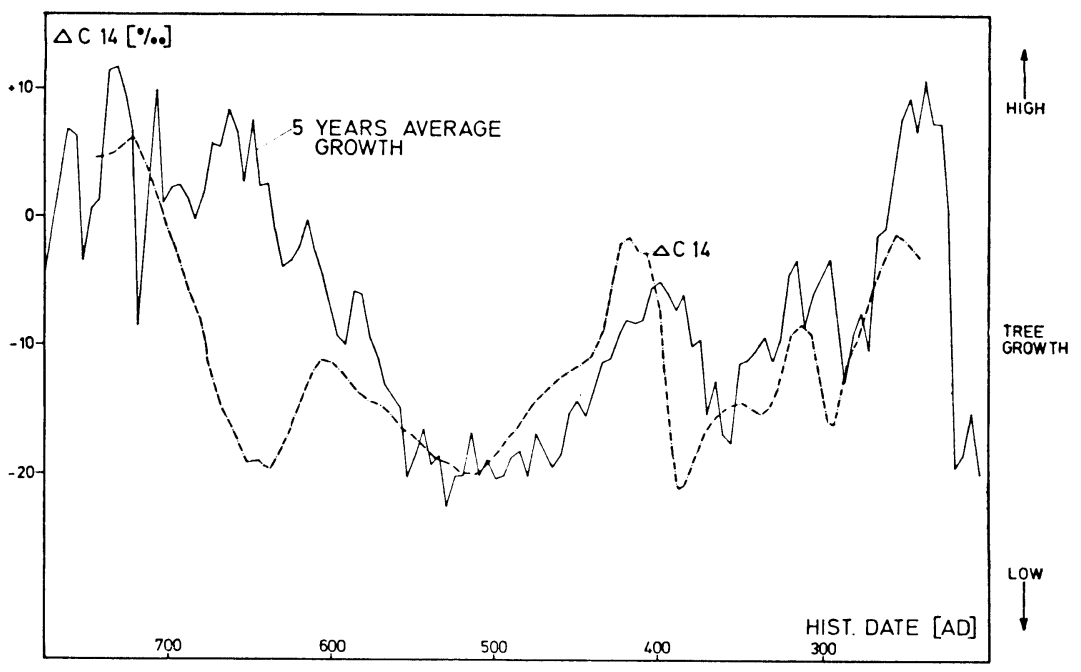

Fig 2. Comparison of 5 -year annual growth of tree rings and $\Delta^{14} \mathrm{C}$ (10-year running means) between AD 200 and 800 .

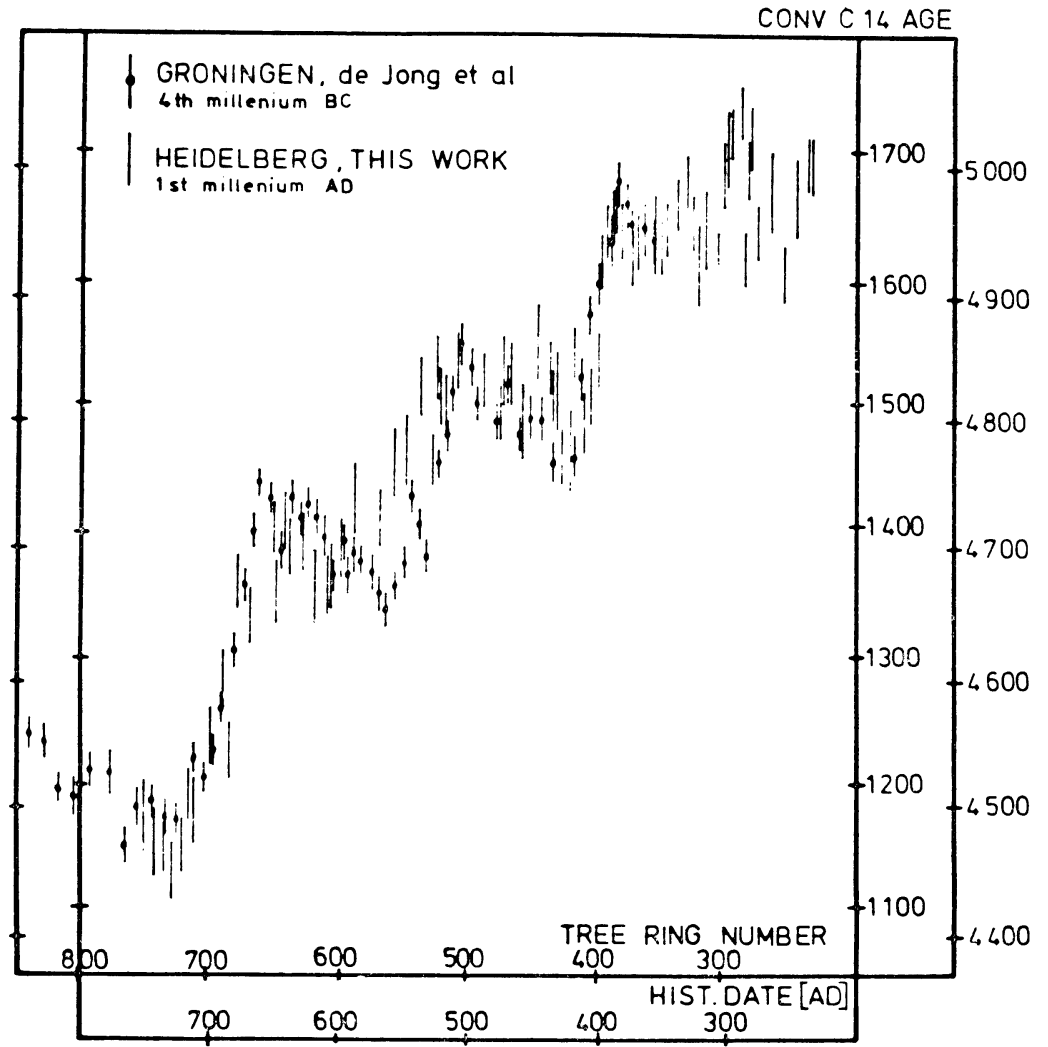

Fig 3. Patterns of atmospheric ${ }^{14} \mathrm{C}$ reflected in European oak series. Floating series 4th millennium BC (de Jong, Mook, and Becker, 1979). Absolutely dated series (Donau 5) 1st millennium AD (this paper). 
Fourier analysis of the data exhibits a periodicity of 150 to 180 years, also found by de Jong and others (1980) using a floating chronology of European oaks. Both series show a very similar pattern, though the second one is about 4000 years older, starting around 3800 BC (fig 3). These results support the findings of Suess (1980), as reflected in his more than 1000 individual measurements covering the last 8000 years, that a pronounced 200-year cycle in atmospheric radiocarbon exists. These variations and the resulting non-unique relationship of conventional radiocarbon age versus historic age of samples may lead to additional errors in dating short-lived samples in archaeology or geology (for example, grains or seeds) of up to \pm 150 years (fig 4 ).

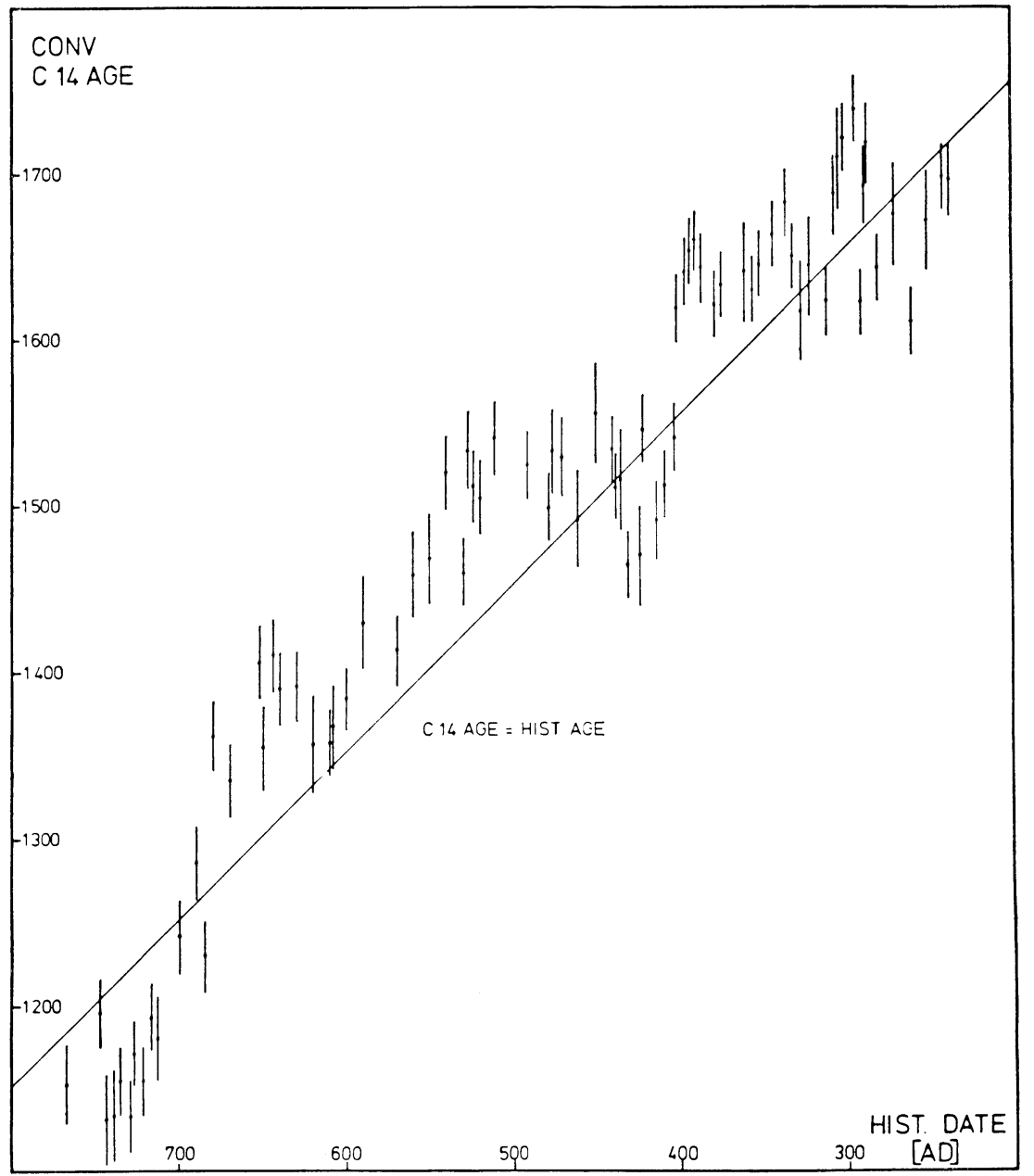

Fig 4. Conventional radiocarbon ages $(\tau=5568)$ versus historic time scale $\mathrm{AD}$ 200 to 800 . 
We recently started measurements on oak material from two floating chronologies covering 7500 to 8700 BP (conventional radiocarbon ages). In addition to short time variations already found, the results will provide some information about the general trend of ${ }^{14} \mathrm{C}$ beyond $6000 \mathrm{BC}$.

\section{ACKNOWLEDGMENT}

We wish to thank the Heidelberg Academy of Sciences for financial support.

\section{REFERENCES}

Becker, Bernd, 1980, Tree-ring dating and radiocarbon calibration in south-central Europe, in Stuiver, Minze and Kra, Renee, eds, Internatl radiocarbon conf, 10th, Proc: Radiocarbon, $v$ 22, no. 2, p 219-226.

Bray, J R, 1967, Variation in atmospheric carbon-14 activity relative to a sunspot auroral solar index: Science, v 156, p 640-642.

Clark, D H and Stephenson, F R, 1978, An interpretation of the pre-telescopic sunspot records from the Orient: Royal astron Soc Quart Jour, v 19, p 387-410.

Eddy, J A, 1976, The Maunder minimum: Science, v 192, p 1189-1202.

Houtermans, J C, Suess, H E, and Oeschger, Hans, 1973, Reservoir models and production rate variations of natural radiocarbon: Jour Geophys Research, v 78, p 1897-1908.

de Jong, A F M and Mook, W G, 1980, Medium-term atmospheric ${ }^{14} \mathrm{C}$ variations, in Stuiver, Minze and Kra, Renee, eds, Internatl radiocarbon conf, 10th, Proc: Radiocarbon, v 22, no. 2, p 267-272.

de Jong, A F M, Mook, W G, and Becker, Bernd, 1979, Confirmation of the Suess wiggles: 3200-3700 BC: Nature, v 280.

Mitchell, J U, 1977, The changing climate, in Energy and climate: Natl Acad Sci, Washington, DC, p 51-58.

Pearson, G W, Pilcher, J R, Baillie, M G, and Hillam, J, 1977, Absolute radiocarbon dating using a low altitude European tree ring calibration: Nature, v 270, p 25.

Schoch, Hilla, Bruns, Michael, Münnich, K O, and Münnich, Marianne, 1980, A multicounter system for high precision carbon-14 measurements, in Stuiver, Minze and Kra, Renee, eds, Internatl radiocarbon conf, 10th, Proc: Radiocarbon, v 22, no. 2, p $442-447$.

Stuiver, Minze, 1961, Variation in radiocarbon concentration and sunspot activity: Jour Geophys Research, v 66, p 273-276.

1978, Radiocarbon timescale tested against magnetic and other dating methods: Nature, v 273, p 271-273.

Suess, H E, 1968, Climatic changes, solar activity, and the cosmic ray production rate of natural radiocarbon: Meteorol mon, $v 8, \mathrm{p}$ 146-150.

$1970 \mathrm{a}$, The three causes of the secular C-14 fluctuations, their amplitudes and time constants, in Olsson, I U, ed, Radiocarbon variations and absolute chronology, Nobel symposium, 12th, Proc: New York, John Wiley and Sons, p 595-612. $1970 \mathrm{~b}$, Bristlecone pine calibration of the radiocarbon time scale $5200 \mathrm{BC}$ to present, in Olsson, I U, ed, Radiocarbon variations and absolute chronology, Nobel symposium, 12th, Proc: New York, John Wiley and Sons, p 303-311.

1978, Radiocarbon time scale tested against magnetic and other dating methods: Nature, v 273, p 271-273.

1980 . The radiocarbon record in tree rings of the last 8000 years, in Stuiver, Minze and Kra, Rence, eds, Internatl radiocarbon conf, 10th, Proc: Radiocarbon, v 22, no. 2, p 200-209.

Suess, H E and Becker, Bernd, 1977, Der Radiocarbongehalt von Jahresring Probaus postglazialen Eichenstämmen Mitteleuropas; Dendrochronologie und postglaziale Klimaschwankungen in Europa: Erdwissenschaftliche Forschung, v 13, p 156-170. 